\title{
Detection of DNA Aberrations in Human Cancers by Single-Strand Conformation Polymorphism Analysis of Polymerase Chain Reaction Products
}

\author{
Yoshinori Murakami, Youichi Suzuki, Yosuke \\ Kishimoto, Setsuo Hirohashi*, Kenshi Hayashi and \\ Takao Sekiya \\ Oncogene Division and *Pathology Division, National \\ Cancer Center Research Institute, Tokyo 104
}

\begin{abstract}
Murakami, Y., Suzuki, Y., Kishimoto, Y., Hirohashi, S., Hayashi, K. and Sekiya, T. Detection of DNA Aberrations in Human Cancers by Single-Strand Conformation Polymorphism Analysis of Polymerase Chain Reaction Products. Tohoku J. Exp. Med., 1992, 168 (2), 247-255 — We have developed a simple, sensitive method, single-strand conformation polymorphism (SSCP) analysis, to detect a single nucleotide substitution in a DNA fragment amplified and labeled by the polymerase chain reaction (PCR). Mobility shift of single-stranded DNAs due to their specific conformations on non-denaturing polyacrylamide gel electrophoresis can reveal DNA aberrations. By the PCR-SSCP analysis of DNAs from surgical specimens of human cancers, mutated ras genes $(17 \%)$ and aberrations of tumor suppressor p53 gene (53\%) including loss of one of the two alleles and a mutation in the remaining allele were detected in lung carcinomas and aberrations of both of the p53 and retinoblastoma (RB) genes were detected exclusively in advanced hepatocellular carcinomas. $\longrightarrow$ SSCP analysis; lung carcinoma; hepatocellular carcinoma; ras gene; p53 gene; RB gene
\end{abstract}

Recent evidence indicates that accumulation of several genetic changes is required for genesis of human cancers. Genetic changes observed in cancer cells include amplification, rearrangement, loss of genes, single-base substitution and deletion or insertion of nucleotides. To characterize human cancers, these five items should be detected and therefore a single technology that can detect almost all of these DNA aberrations is desirable. The method must be simple and sensitive. Combined use of the polymerase chain reaction (PCR) (Saiki et al. 1988), single-strand conformation polymorphism (SSCP) analysis (Orita et al. 1989a) and direct DNA sequencing (Gyllensten and Erlich 1988) can provide a powerful procedure for detection and identification of mutations in DNA and also in RNA.

The SSCP analysis that we have developed is a method to detect a single

Address for reprints : Tsukiji 5-chome, Chuo-ku, Tokyo 104, Japan. 
nucleotide substitution in a DNA fragment. If a double-stranded DNA fragment is denatured to complementary single strands, each strand forms a specific tertiary structure depending on its nucleotide sequence. The complementary strands with a different conformation can be separated by electrophoresis in non-denaturing polyacrylamide gel (Maxam and Gilbert 1980). We found that a singlenucleotide substitution in a given single-stranded DNA resulted in a different conformation and could be detected by a mobility shift on the gel electrophoresis (Orita et al. 1989a). SSCP analysis of DNA fragments amplified and labeled by the PCR provides a simple, sensitive method for detection of single-nucleotide substitutions (Orita et al. 1989b).

By the PCR-SSCP analysis of DNAs from surgical specimens of human cancers, mutated ras genes and aberrations of tumor suppressor p53 and retinoblastoma $(\mathrm{RB})$ genes were analyzed. In lung carcinomas, ras gene mutations and aberrations of the p53 gene were occurred independently and these abnormalities were observed in a variety of histological types and clinical stages. In hepatocellular carcinomas (HCCs), structural abnormalities of the p53 gene were observed exclusively in advanced carcinomas. Furthermore, loss of the RB gene was coincidentally observed in HCCs carrying the mutated p53 gene.

\section{Materials and Methods}

Tumor specimens. Fresh specimens of primary tumors and noncancerous tissues were obtained at operation from patients with lung or liver cancers at the National Cancer Center Hospital, Tokyo, Japan.

Preparation of DNA and PCR-SSCP analysis. Genomic DNA was prepared by the proteinase K-phenol-chloroform extraction method (Blin and Stafford 1976). DNA sample $(0.1 \mu \mathrm{g})$ were subjected to the polymerase chain reaction in the mixture $(5 \mu \mathrm{l})$ described previously (Orita et al. 1989b) using two appropriate oligonucleotides labeled with ${ }^{32} \mathrm{P}$ at the $5^{\prime}$-ends as primers. The PCR mixture was heated at $80^{\circ} \mathrm{C}$ with $45 \mu \mathrm{l}$ of formamide dye mixture (95\% formamide- $20 \mathrm{mM}$ EDTA- $0.05 \%$ xylene cyanol- $0.05 \%$ bromphenol blue), and then $1 \mu \mathrm{l}$ of the preparation was applied to $5 \%$ polyacrylamide gel with or without $10 \%$ glycerol. Electrophoresis was performed at $40 \mathrm{~W}$ for 2 to $4 \mathrm{hr}$ in $45 \mathrm{mM}$ Tris-borate ( $\mathrm{pH}$ 8.3) with cooling by a fan. The gel was dried on filter paper and exposed to $x$-ray film at $-80^{\circ} \mathrm{C}$ for 1 to $12 \mathrm{hr}$ with an intensifying screen.

Direct DNA sequencing. Nucleotide sequences were determined by the dideoxy chain termination method with asymmetric PCR products (Gyllensten and Erlich 1988). DNA fragments showing mobility shift by PCR-SSCP analysis were separated by and eluted from polyacrylamide gel as previously described (Suzuki et al. 1991), and they were amplified by 50 cycles of the asymmetric PCR with an uneven molar ratio $(10: 1)$ of the primers. The reaction mixture was diluted and deionized in a Centricon 30 microconcentrator (Amicon, Beverly, MA, USA), and the amplified single-stranded DNAs were annealed to a 5'-labeled primer. Chain elongation and termination were performed using a Sequenase kit (United States Biochemical Corporation, Cleaveland, OH, USA), and products were analyzed in $6 \%$ polyacrylamide gel containing $7 \mathrm{M}$ urea.

\section{RESULTS}

PCR-SSCP analysis of the ras genes in human lung cancers. We analyzed 
the ras genes in DNAs from 129 surgical specimens of lung carcinoma by the PCR-SSCP method (Suzuki et al. 1990). Nucleotide sequences of the synthetic deoxyoligonucleotides used in the PCR as primers and the amplified regions carrying exon 1 or 2 of the c-Ki-ras2 gene (162 or 128 base pairs (bp), respectively), the c-Ha-ras 1 gene (110 or $194 \mathrm{bp}$, respectively) and the $\mathrm{N}$-ras gene (118 and 103 $\mathrm{bp}$, respectively) were described previously (Suzuki et al. 1990). Representative results obtained using primers for exon 1 of the c-Ki-ras2 gene are shown in Fig. 1. The other regions were analyzed similarly and mobility shifts were detected. Of 129 lung carcinomas, 22 (17\%) showed mobility shifts.

To determine the nucleotide substitutions detected by mobility shifts of single-stranded DNA fragments, the DNA samples that showed mobility shifts were subjected to direct sequencing by the asymmetric PCR method (Gyllensten and Erlich 1988). Activation of the c-Ki-ras2 gene was found in 16 tumors, 8 with mutation in codon 12,4 with a mutation in codon 13 , one in codon 18 and 3 with a mutation in codon 61 . Activation of the $\mathrm{N}$-ras gene was found in 3 tumors, one with a mutation in codon 12 and 2 with a mutation in codon 61 . Three other tumors carried a c-Ha-ras 1 gene with a mutation in codon 61 .

As summarized in Table 1, activation of the ras gene was observed most frequently in adenocarcinomas $(24 \%)$, but was also found in large cell carcinomas $(21 \%)$ and squamous cell carcinomas $(8 \%)$. Few small cell carcinomas and adenosquamous carcinomas were examined, but none of them carried an activated

\section{$\begin{array}{llllllllllllllllll}1 & 2 & 3 & 4 & 5 & 6 & 7 & 8 & 9 & 10 & 11 & 12 & 13 & 14 & 15 & 16 & 17 & 18\end{array}$}

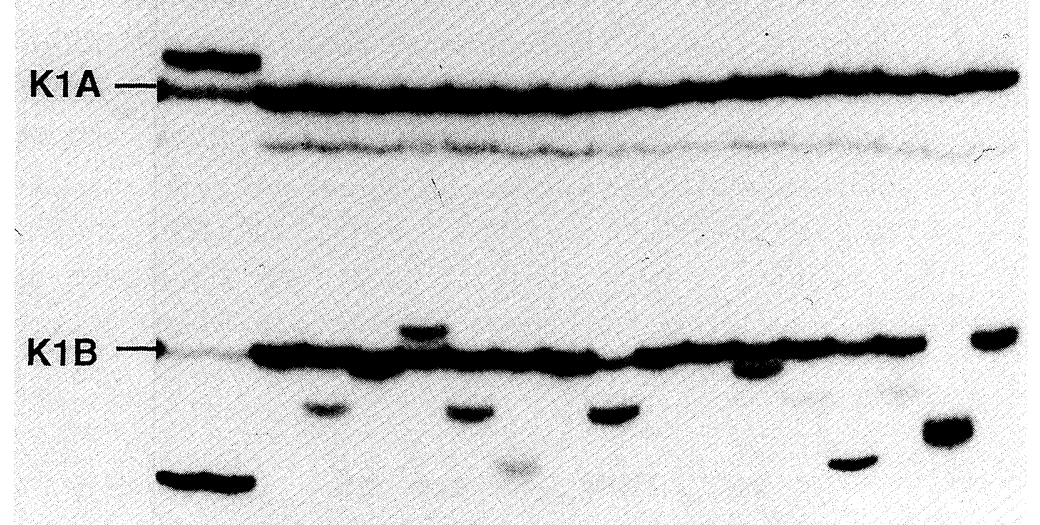

Fig. 1. Detection of point mutations of the ras gene in surgical specimens of human lung cancer. DNA fragments of $162 \mathrm{bp}$ amplified by the PCR from the region of exon 1 of the $\mathrm{Ki}$-ras 2 gene were subjected to the SSCP analysis. $\mathrm{K} 1 \mathrm{~A}$ and $\mathrm{K} 1 \mathrm{~B}$ represent the separated strands with the normal nucleotide sequence. In this particular experiment, electrophoresis was performed at $40 \mathrm{~W}$ for $2.5 \mathrm{hr}$ in $6 \%$ non-denaturing polyacrylamide gel without glycerol at $4^{\circ} \mathrm{C}$. 
TABLE 1. Pathological features of human lung cancers and mutated ras and p53 genes

\begin{tabular}{lrcrr}
\hline & \multicolumn{2}{c}{ Number of tumor } & \multicolumn{2}{c}{ Number of tumor } \\
\cline { 2 - 5 } . Pathological feature & Analyzed & $\begin{array}{c}\text { With mutated } \\
\text { ras gene (\%) }\end{array}$ & Analyzed & $\begin{array}{r}\text { With mutated } \\
\text { p53 gene (\%) }\end{array}$ \\
\hline Histology & 121 & $22(18)$ & 116 & $60(52)$ \\
$\quad$ Non-samll cell carcinoma & 14 & $3(21)$ & 14 & $8(57)$ \\
$\quad$ Large cell carcinoma & 66 & $16(24)$ & 58 & $24(41)$ \\
$\quad$ Adenocarcinoma & 36 & $3(8)$ & 37 & $25(68)$ \\
$\quad$ Squamous cell carcinoma & 5 & 0 & 6 & $3(50)$ \\
$\quad$ Adenosquamous carcinoma & 8 & 0 & 6 & $5(83)$ \\
Small cell carcinoma & & & & \\
Pathological stage & 34 & $5(15)$ & 34 & $15(44)$ \\
I & 10 & $3(30)$ & 10 & $4(40)$ \\
II & 58 & $9(16)$ & 58 & $37(65)$ \\
III & 21 & $5(24)$ & 20 & $8(38)$ \\
IV & 6 & 0 & 0 & 0 \\
Unknown & & & & \\
& 129 & $22(17)$ & 122 & $65(53)$ \\
\hline
\end{tabular}

ras gene.

PCR-SSCP analysis of the p53 gene in human lung carcinomas. In 122 of 129 DNA samples from surgical specimens of human lung cancer that were analyzed for mutations of the ras genes, we also examined aberrations of the p53 gene by the PCR-SSCP method (Kishimoto et al. details will be published elsewhere). As shown in Fig. 2, nine DNA fragments (A to I) each containing one or two of exons 2 to 11 were amplified using nine sets of primers and amplified fragments were subjected to SSCP analysis. As representative results, analysis of fragment $\mathrm{F}$ carrying the nucleotide sequence of exon 7 from 25 tumors is shown in Fig. 3. DNA samples in lanes 10, 12, 17, 22, 24 and 25 showed apparent mobility shifts. By analysis of nine fragments from 122 tumors, total 65 frag-

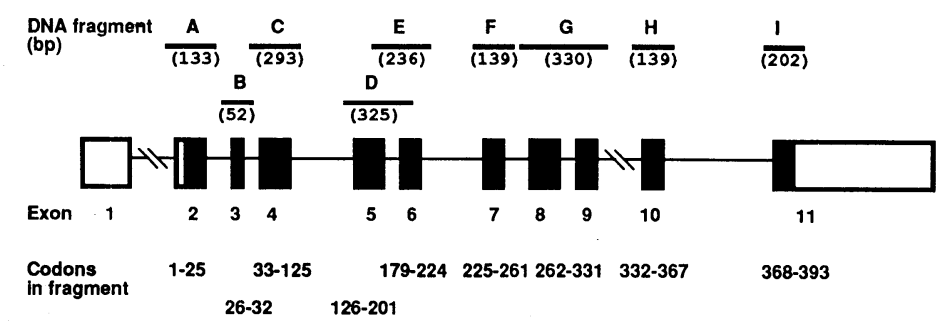

Fig. 2. Regions of the p53 gene subjected to PCR-SSCP analysis. 


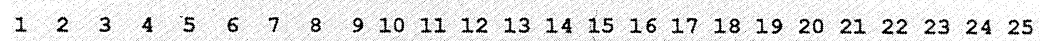

Fig. 3. SSCP analysis of fragment $\mathrm{F}$ carrying the region of exon 7 of the p53 gene in DNAs from human lung cancers.

ments with an abnormal mobility were detected in 62 tumors. In three other tumors, we observed loss of the p53 allele, but not mobility shift in any fragment. Therefore, aberrations of the p53 gene were observed in 65 of 122 tumors (53\%). Among these tumors, allele loss of the p53 gene was observed in 17 of 35 informative cases $(46 \%)$.

To identify the nucleotide sequence alterations detected by PCR-SSCP analysis, single-stranded DNA fragments with abnormal mobility were eluted from the SSCP gel and subjected to direct DNA sequencing procedure. Of 65 mutations identified, $50(77 \%)$ were single-base substitutions (43 missense mutations, 5 nonsense mutations and 2 splicing mutations), 3 were two-base substitutions (missense mutations) and 13 were either deletion or insertion of one to several bases (frame shift or amino acid-deletion mutations). Of 46 missense mutations, $39(85 \%)$ were observed in exons 5,7 and 8 .

As summarized in Table 1, aberrations of the p53 gene in lung cancers are not restricted to a particular histological type and a clinical stage.

PCR-SSCP analysis of the p53 and RB genes in human hepatocellular carcinomas. We analyzed the p53 gene in DNAs from 43 surgical specimens of HCC by the PCR-SSCP method (Murakami et al. 1991b). Of these HCCs, 22 were advanced carcinomas and 21 were early carcinomas. Analysis of nine fragments from the p53 gene (Fig. 1) revealed that DNA samples from eight tumors showed a mobility shift in one or two of the fragments. Of the eight tumors with abnormal p53 gene, seven had lost one of the two p53 alleles. Nucleotide sequence analysis revealed that four carried a point mutation, two had a deletion of several nucleotides in the remaining allele of these seven tumors and one did not have any identifiable mutation. The remaining one retained both alleles and carried two point mutations at codons 175 and 272. As summarized in Table 2, no aberration of the p53 gene was observed in the 21 early HCCs. The mutations of the p53 gene detected were all in the advanced HCCs, 4 in moderate- 
TABLE 2. Aberration of the p53 gene and pathological parameters of hepatocellular carcinomas

\begin{tabular}{ccc}
\hline \multirow{2}{*}{ Parameter } & \multicolumn{2}{c}{ Number of tumors } \\
\cline { 2 - 3 } & Analyzed & $\begin{array}{c}\text { Aberration of } \\
\text { the p53 gene (\%) }\end{array}$ \\
\hline Histological differentiation & 21 & 0 \\
Early carcinoma & 22 & $8(36)$ \\
Advanced carcinoma & 3 & 0 \\
Well differentiated & 11 & $4(36)$ \\
Moderately differentiated & 8 & $4(50)$ \\
Poorly differentiated & & \\
Tumor size & 18 & 0 \\
$<2 \mathrm{~cm}$ & 6 & $1(14)$ \\
$2-3 \mathrm{~cm}$ & 19 & $7(37)$ \\
$>3 \mathrm{~cm}$ & &
\end{tabular}

ly differentiated $(36 \%)$ and 4 in poorly differentiated (50\%) HCCs. Grouping the HCCs according to size indicated that almost all the aberrations of the gene were present in tumors of more than $3 \mathrm{~cm}$ in diameter. These results indicated the involvement of aberrations of the p53 gene in less differentiated and advanced HCCs. We also examined loss of the RB gene in HCCs by detecting a nucleotide sequence polymorphism in intron 25 of the gene using PCR-SSCP method. Loss of heterozygosity was observed in 6 of 7 informative cases of 8 tumors with a mutated p53 gene, but not in 17 informative cases without a p53 mutation (Murakami et al. 1991b). These results suggested that mutations in both the p53 and RB genes were involved in development of HCCs.

\section{Discussion}

Examination of the ras oncogene and the p53 and RB genes in DNAs from surgical specimens of human lung and liver cancers by the PCR-SSCP analysis showed that this method was effective for detecting point mutations and other small DNA changes at an unknown position in a given DNA fragment. The PCR-SSCP method is especially useful for analysis of DNAs from surgical specimens of tumor tissues. Usually tumor tissues contain normal cells besides tumor cells and sometimes the population of tumor cells in surgical specimens is less than $10 \%$ of the total cells. In the DNAs of these particular specimens point mutations cannot readily be detected by the conventional methods such as allelespecific oligonucleotide hybridization, RNase A-mismatch cleavage analysis or direct DNA sequencing. However, the PCR-SSCP method detects nucleotide substitutions as mobility shifts of single-stranded DNA fragments and, therefore, can easily detect point mutations in less than $10 \%$ of the total DNA. 
Furthermore, this method is suitable for analyzing aberrations of tumor suppressor genes. In many cases examined, inactivation of the p53 and RB genes has been found to be due to loss of one of the two alleles and a point mutation or a small deletion in the other allele. The PCR-SSCP method can detect both loss of a gene and a subtle genetic change in the remaining allele at the same time (Murakami et al. 1991a, b).

By the oligonucleotide hybridization technique, Rodenhuis et al. (1988) detected point-mutational activation of the ras gene exclusively in adenocarcinomas of the lung with a frequency of $33 \%$ (15 of 45$)$ and found that 14 of the 15 activated ras genes were c-Ki-ras 2 genes, all with a mutation in codon 12 and the remaining one was the c-Ha-ras 1 gene with a mutation in codon 12 . By the PCR-SSCP method, we detected activation of the ras gene in adenocarcinomas of the lung at lower frequency $(24 \%, 16$ of 66$)$ than that reported by Rodenhius et al. (1988) and found that the ras genes activated in the adenocarcinomas were not restricted to the c-Ki-ras 2 gene. Furthermore, the point mutations of the c-Kiras 2 gene found in the adenocarcinomas were not restricted to codon 12 , genes with a mutated codon 12 amounting to less than half of the total mutated c-Ki-ras2 gene (6 of 14).

Although recent studies have indicated that the wild-type p53 gene is a tumor suppressor gene, the p53 protein was first found in cells transformed with SV40 as a cellular protein bound to the SV40 large tumor antigen and over expression of the p53 protein encoded by the mutated p53 gene but not by the wild-type gene could transform early passaged rodent cells in conjunction with an activated ras gene product (Finlay et al. 1989 ; Hinds et al. 1989). To elucidate the relationship between ras gene mutations and abnormalities of the p53 gene, aberrations of the p53 gene in the DNA samples from surgical specimens of human lung cancer that were analyzed for ras gene mutations were detected by the PCR-SSCP method. Frequency of the aberrations observed were quite high (53\%, 65 of 122 tumors). However, the frequency of the p53 gene mutations in the lung cancers $(53 \%)$ and in the carcinomas with the mutated ras gene $(46 \%)$ were essentially the same, suggesting that mutations in the ras and p53 genes occurred independently.

Mutations of the p53 gene were found in all histological types of lung carcinomas and were not restricted to a particular differentiated state nor a clinical stage. As observed previously, the mutations in small cell carcinomas were very frequent $(83 \%)$. The aberrations were also frequent in non-small cell carcinomas $(52 \%)$ with a higher frequency in squamous cell carcinomas $(68 \%)$ compared to the other types (41-57\%).

Analysis of 43 surgical specimens of human HCC revealed aberrations of the p53 gene in 8 of 22 advanced carcinomas, but not in any of the 21 early carcinomas examined, suggesting that these aberrations were involved in a late stage of $\mathrm{HCC}$ development. Although a germinal mutation of the p53 gene in Li-Fraumeni syndrome was recently reported (Markin et al. 1990), aberrations of the p53 gene 
in a late stage of tumorigenesis have also been observed in colon cancers (Fearon and Vogelstein 1990).

We observed coincident abnormalities of the p53 and RB genes in advanced HCCs, suggesting the involvement of at least two tumor suppressor genes in a late stage of the carcinogenesis of HCCs. Aberrations of both these tumor suppressor genes have also been observed in small cell lung cancers (Yokota et al. 1987) and soft tissue sarcomas (Stratton et al. 1990).

\section{References}

1) Blin, N. \& Stafford, D.M. (1976) A general method for isolation of high-molecularweight DNA from eukaryotes. Nucleic Acids Res., 3, 2303-2308.

2) Fearon, E.R. \& Vogelstein, B. (1990) A genetic model for colorectal tumorigenesis. Cell, 61, 759-767.

3) Finlay, C.A., Hinds, P.W. \& Levine, A.J. (1989) The p53 proto-oncogene can act as a suppressor of transformation. Cell, 57, 1083-1093.

4) Gyllensten, U.B. \& Erlich, H.A. (1988) Generation of single-strand DNA by the polymerase chain reaction and its application to direct sequencing of the HLA-DQA locus. Proc. Natl. Acad. Sci. USA, 85, 7652-7656.

5) Hinds, P., Finlay, C. \& Levine, A.J. (1989) Mutation is required to activate the p53 gene for cooperation with the ras oncogene and transformation. $J$. Virol., 63, 739746.

6) Markin, D., Li, F., Strong, F.P., Fraumeni, J.F., Jr., Nelson, C.E., Kim, D.H., Kassel, J., Gryka, M.A., Bischoff, F.Z., Tainsky, M.A. \& Friend, S.H. (1990) Germ line p53 mutations in a familiar syndrome of breast cancer, sarcomas, and other neoplasms. Science, 250, 1233-1238.

7) Maxam, A.M. \& Gilbert, W. (1980) Sequencing end-labeled DNA with base-specific chemical cleavages. Methods Enzymol., 65, 499-560.

8) Murakami, Y., Hayashi, K. \& Sekiya, T. (1991a) Detection of aberrations of the p53 alleles and the gene transcript in human tumor cell lines by single-strand conformation polymorphism analysis. Cancer Res., 51, 3356-3361.

9) Murakami, Y., Hayashi, K., Hirohashi, S. \& Sekiya, T. (1991b) Aberrations of the tumor suppressor p53 and retinoblastoma genes in human hepatocellular carcinomas. Cancer Res., 51, 5520-5525.

10) Orita, M., Iwahana, H., Kanazawa, H., Hayashi, K. \& Sekiya, T. (1989a) Detection of polymorphisms of human DNA by gel electrophoresis as single-strand comformation polymorphisms. Proc. Natl. Acad. Sci. USA, 86, 2766-2770.

11) Orita, M., Suzuki, Y., Sekiya, T. \& Hayashi, K. (1989b) Rapid and sensitive detection of point mutations and DNA polymorphisms using the polymerase chain reaction. Genomics, 5, 874-879.

12) Rodenhuis, S., Slebos, R.J.C., Boot, A.J.M., Evers, S., Mooi, W.J., Wagenaar, S.S., van Bodengom, P.C. \& Bos, J.L. (1988) Incidence and possible clinical significance of $\mathrm{K}$-ras oncogene activation in adenocarcinoma of the human lung. Cancer Res., 48, 5738-5741.

13) Saiki, R.K., Gelfand, D.H., Stoffel, S., Scharf, S.J., Higuchi, R., Horn, G.T., Mullis, K.B. \& Erlich, H.A. (1988) Primer-directed enzymatic amplification of DNA with a termostable DNA polymerase. Science, 239, 487-491.

14) Stratton, M.R., Moss, S., Warreen, W., Patterson, H., Clark, J., Fisher, S., Fletcher, C.D., Ball, A., Thomas, M., Gusterson, B.A. \& Cooper, C.S. (1990) Mutation of the p53 gene in human soft tissue sarcomas : Association with abnormalities of the RB1 gene. Oncogene, 5., 1297-1301. 
15) Suzuki, Y., Orita, M., Shiraishi, M., Hayashi, K. \& Sekiya, T. (1990) Detection of ras gene mutations in human lung cancers by single-strand conformation polymorphism analysis of polymerase chain reaction products. Oncogene, 5, 1037-1043.

16) Suzuki, Y., Sekiya, T. \& Hayashi, K. (1991) Allele-specific polymerase chain reaction: A method for amplification and sequence determination of a single component among a mixture of sequence variants. Anal. Biochem., 192, 82-84.

17) Yokota, J., Wada, M., Shimosato, Y., Terada, M. \& Sugimura, T. (1987) Loss of heterozygosity on chromosome 3,13 , and 17 in small-cell carcinoma and chromosome 3 in adenocarcinoma of the lung. Proc. Natl. Acad. Sci. USA, 84, 9252-9256. 